\title{
MEMBANGUN KEIMANAN DAN TOLERANSI BERAGAMA MELALUI MODEL PEMBELAJARAN HIWAR JADALİ DI MASA PANDEMI COVID-19
}

\author{
Munawar Rahmat dan Endis Firdaus*
}

Universitas Pendidikan Indonesia, Indonesia

*E-mail: endis@@upi.edu

\begin{abstract}
Religious tolerance among students is quite problematic. The results of previous studies showed that student's intolerance was quite high. The question is, how to teach students a solid faith and be tolerant of other religions and different Islamic groups? Abdurrabman An-Nablawi, An Islamic Scholar and Professor of Islamic Education in Egypt introduced seven types of Quranic methods, one of which is Hiwar Jadali (dialogue-argumentative Qurani). This method is thought to strengthen faith as well as religious tolerance of students, provided that the lecturer can choose the right verses. This study aims to produce Hiwar Jadali learning model in Islamic Religious Education to strengthen the religious belief and tolerance of UPI students. This research uses descriptive-comparative method. Two classes used the Hiwar Jadali learning model while the other two classes used the ordinary model. As a result, Hiwar Jadalī's learning model was proven to be more effective in strengthening students' faith and religious tolerance.
\end{abstract}

Keywords: learning model; Hiwar Jadali; faith; religious tolerance

\begin{abstract}
Abstrak. Toleransi beragama di kalangan mahasiswa cukup bermasalah. Hasil-hasil penelitian terdahulu menunjukkan intoleransi mahasiswa cukup tinggi. Pertanyaannya, bagaimanakah mengajarkan keimanan yang kokoh kepada mahasiswa sekaligus toleran terhadap agama dan golongan Islam lain yang berbeda?. Abdurrahman An-Nablawi, Ulama dan Guru Besar Pendidikan Islam Mesir mengenalkan tujuh jenis metode Qurani, salah satunya Hiwar Jadalī (dialog-argumentatif Qurani). Metode ini diduga dapat mengokobkan keimanan sekaligus toleransi beragama bagi mahasiswa, dengan catatan dosen dapat memilih penggalan ayat-ayat yang tepat. Penelitian ini bertujuan menghasilkan model pembelajaran Hiwar Jadali dalam Pendidikan Agama Islam untuk mengokobkan keimanan dan toleransi beragama mahasiswa UPI. Penelitian ini menggunakan metode deskriptif-komparatif. Dua kelas menggunakan model pembelajaran Hiwar Jadalī sedangkan dua kelas lainnya menggunakan model biasa. Hasilnya, model pembelajaran Hiwar Jadalī terbukti lebih efektif mengokobkan keimanan dan toleransi beragama mahasiswa.
\end{abstract}

Kata Kunci: Model pembelajaran; Hiwar Jadali; Keimanan; Toleransi Beragama 


\section{PENDAHULUAN}

Pendidikan keimanan perlu ditanamkan secara benar. Di dunia akademik pendidikan keimanan biasanya diajarkan secara konvensional dengan mengajarkan sifat-sifat Allah yang 13 atau 20, Asma ul Husna, dan kajian rukun iman dengan menyebutkan dalil-dalil Al-Quran tentang keberadaan Allah, Malaikat-malaikatNya, Kitab-kitabNya, Rasul-rasulNya, Hari Akhir, dan qodho-qodarNya. Di sisi lain ada juga pendekatan rasional-filosofis terhadap keberadaan Tuhan dan rukun iman. Baik pendekatan konvensional ataupun rasional sebenarnya hanya mengantarkan kepada keraguan. Mengapa ragu? Karena kedua pendekatan hanya mendatangkan kontroversi yang tidak berkesudahan. Di antara kontroversi pendekatan konvensional misalnya tentang sifat Allah yang 13 atau 20 versi hanya satu sifat Tuhan. Kedua versi ini sebenarnya rasional juga, lebih tepatnya rasional klasik. Versi 13 sifat menegaskan bahwa urut-urutan mulai sifat Wujud (Ada, sedangkan makhluk diadakan), Qidam (Terdahulu, sedangkan makhluk datang kemudian), Baqa (Kekal-Abadi, sedangkan makhluk fana`hancur), Mukbolafatu lil hawaditsi (Berbeda dengan makhluk), Qiyamubu bi nafsibi (Berdiri sendiri, sedangkan makhluk diciptakan), dan seterusnya hingga Kalam (Berfirman, sepertinya sama makhluk juga bisa berbicara, tapi Berfirman Allah berbeda dengan berbicara makhlukNya) merupakan urutan yang gradual. Maksudnya, urutan pertama (sifat $W$ ujud) merupakan sifat yang paling pokok dan mendasar. Dari sifat Wujud inilah kemudian muncul (secara rasional, bukan secara waktu) sifat Qidam, dan seterusnya muncul sifat Kalam. Sifat 20 merupakan kelanjutan logis dari sifat 13. Di sekolah, sebagaimana di pesantren, pendekatan konvensional inilah yang diajarkan. Bahkan sifat 13 atau 20 ini dihapalkan. Anak-anak dan masyarakat muslim santri umumnya menghapalnya, walau mereka kurang mengerti akan maksud sifat 13 atau 20 ini. Adapun versi hanya Satu Sifat Tuhan menegaskan bahwa segala kesempurnaan merupakan Sifat Tuhan. Sifat 13, sifat 20, atau Asma`ul Husna dipandangnya membatasi Sifat Tuhan yang Maha Sempurna. Di antara kontroversi pendekatan rasional-filosofis misalnya ayat-ayat Al-Quran, apakah benar Firman Allah ataukah Sabda Nabi? Satu mazhab mengatakan Firman Allah, sedangkan mazhab lainnya mengatakan Sabda Nabi. Kedua mazhab ini saling menyalahkan. Untungnya kedua mazhab sepakat bahwa Al-Quran adalah mutlak benarnya, tidak ada satu kata pun yang diragukan kebenarannya. Atas dasar hal ini mengapa kaum muslimin tidak merujuk langsung Al-Quran saja, padahal Kitab Suci ini punya cara sendiri di dalam meyakinkan para pembacanya.

Di sisi lain toleransi beragama di kalangan mahasiswa cukup bermasalah. Hasil penelitian terdahulu, corak berpikir keagamaan mahasiswa aktivis Islam UPI khususnya dan 10 PTN/PTS di Jawa Barat umumnya cenderung eksklusif dan radikal (Rahmat, 2012). Hasil penelitian akhir-akhir ini, tahun 2018, hampir separoh responden mahasiswa UPI memiliki corak berpikir keagamaan yang eksklusif, selebihnya netral dan moderat/toleran (Rahmat \& Fahrudin, 2018). Hasil penelitian tahun 2019, 
sebanyak 49\% responden mahasiswa UPI (termasuk mahasiswa prodi IPAI) intoleran, 26\% netral, dan hanya 25\% yang toleran (Firdaus \& Rahmat, 2019). Sumber intoleransi mereka karena pemahaman mereka tentang maknamakna mukmin, ahli kitab, dan kafir yang lebih mengikuti penafsiran media social ketimbang Al-Quran. Mereka mengatakan, setiap orang Islam otomatis beriman; dan setiap penganut non Islam otomatis kafir. Mahasiswa prodi IPAI pun demikian. Ketika menjawab soal ujian Ilmu Akhlak tentang status keimanan/kekafiran penganut agama di luar Islam, sebagian mereka menjawab "setiap orang Islam otomatis beriman dan setiap orang di luar Islam otomatis kafir." Padahal tidak ada satu ayat AlQuran pun yang menyebutkan demikian. Al-Quran bahkan menegaskan bahwa di antara ahli kitab (penganut agama di luar Islam) ada yang beriman (QS 3/Ali Imran: 199, dll), sebagian lainnya kafir (QS 2/Al-Baqarah: 105, dll). Bahkan mereka mengatakan orang Islam di luar mainstrain, Syìh dan Ahmadiyah, kafir juga. Mahasiswa prodi IPAI pun ketika ditanya status keimanan/kekafiran orang Islam di luar mainstrain sebagian mereka menjawab "Syi'ah dan Ahmadiyah kafir." Padahal Nabi SAW melarang menuduh kafir terhadap sesama muslim (HR Bukhari, dalam Bukhari, 2013 \& HR Muslim, dalam Muslim, 2013). Pesan Imam Ghazali kepada para hakim Islam, jika kalian menemukan 99 ciri kekafiran dari seorang muslim (yang dituduh murtad/kafir) tapi kalian menemukan satu ciri keislaman maka putuskanlah si tertuduh sebagai muslim (Hosen, 2017). Konstitusi Negara menjamin kebebasan beragama bagi setiap warga negara. Para tokoh bangsa dan pemuka agama sering mendengungkan perlunya warga negara untuk menjalankan agama sesuai dengan keyakinannya masing-masing serta menghargai agama dan penganut agama berbeda. Kasus Siska, mahasiswi UPI bercadar yang ditangkap di Mako Brimob Tanggerang (Suara.com, 2018), cukup menjadi perhatian publik dan menguras pemikiran para pemimpin dan para dosen yang berpola piker moderat dan anti radikalisme beragama. Fakta terakhir seorang alumni UPI memberikan pengkaderan kepada para mahasiswa. Dalam pengkaderan tersebut ia tanpa tedeng aling menuduh dosen PAI UPI yang punya paham di luar dirinya, khususnya lagi yang dituduh liberal, sebagai dosen kafir. Ia bahkan menegaskan bahwa menuduh kafir terhadap dosen yang demikian dapat pahala besar. Dari sisi aqidah Islam tentu tuduhan demikian sangat bermasalah. Pertama, ia melanggar hadits Nabi SAW yang melarang menuduh seseorang kafir; dan kedua, takfir (menuduh seseorang kafir) hanyalah hak prerogative Allah dan RasulNya. Artinya dia sudah mengangkat dirinya setingkat Rasulullah. Na`udzu billabi min dzalik. Tentu kasus ini merupakan fenomena gunung es, yang tertangkap seorang tapi yang berpola pikir intoleran dan radikal tentu banyak. Atas dasar fenomena ini maka tujuan, bahan, dan model pembelajaran PAI perlu menambahkan satu karakter, yakni mengembangkan karakter toleran dan anti radikalisme beragama berbasis keimanan yang kokoh.

Abdurrahman An-Nahlawi (1996) mengenalkan tujuh jenis metode AlQuran dalam menyajikan kebenaran (Surahman, 2019). Ketujuh jenis metode 
ini oleh dosen-dosen PAI UPI dikembangkan menjadi model-model pembelajaran Qurani. Adapun metode yang diduga paling tepat untuk mengokohkan keimanan dan toleransi beragama mahasiswa adalah Hiwar Jadali (dialog-argumentatif Qurani). Oleh karena itulah efektivitas model pembelajaran ini perlu diteliti.

Pengembangan karakter religious merupakan aspek fundamental dari keseluruhan sistem pendidikan Nasional, karena pada hakekatnya pendidikan adalah menginsan-kamikan manausia; atau meningkatkan derajat manusia, yang perspektif Al-Quran berkarakter buruk, menjadi manusia yang sempurna (Rahmat, 2017). Keimanan merupakan fondasi religious seseorang. Dalam QS Saba' ayat 51-54 manusia cenderung memiliki keimanan yang keliru, yakni merasa beriman padahal di sisi Allah tidak beriman. Karena itu keimanan perlu ditanamkan secara benar. Adapun referensi utama sumber pembelajaran keimanan seharusnya mengacu langsung kepada Al-Quran.

Konferensi Dhakkar menghasilkan 4 kemampuan yang perlu dikembangkan dalam pendidikan, yakni learning to know, learning to do, learning to be, dan learning to live together (Aspin \& Chapman, 2006). Terlebih-lebih dalam sistem pendidikan nasional, pendidikan agama dan akhlak (karakter) menduduki peranan yang sangat penting dan strategis. Dalam UUSPN Tahun 2003 Bab II pasal 3 disebutkan: Pendidikan nasional berfungsi mengembangkan kemampuan dan membentuk watak serta peradaban bangsa yang bermartabat dalam rangka mencerdaskan bangsa, bertujuan untuk berkembangnya potensi peserta didik agar menjadi manusia yang berîman dan bertakwa kepada Tuhan Yang Maha Esa, berakhlak mulia, sehat, berilmu, cakap, kreatif, mandiri dan menjadi warga negara yang demokratis serta bertanggung jawab. Jika mengacu kepada UUSPN, maka pendidikan nasional Indonesia seharusnya sarat dengan pembelajaran yang berdimensi agama dan karakter. Untuk itu perlu dicari solusi bagaimanakah mendekatkan praktek pendidikan dengan perundangundangan, jangan sampai praktek pendidikan itu mengkhianati amanat perundang-undangan.

Islam adalah sebuah agama yang memiliki ajaran yang lengkap dan sempurna (QS 5/Al-Maidah: 3). Pendidikan formal yang melalui Pendidikan Agama Islam di Indonesia tidak mungkin mampu menjelaskan kelengkapan dan kesempurnaan agama Islam, antara lain karena jam pendidikan agama sangat minim (hanya 2 jam perminggu, bahkan di PTN hanya 2-4 SKS dari total perkuliahan program S-1). Tidakalah heran jika Tilaar (1999: 99) mengemukakan bahwa pendidikan agama dalam kurikulum pendidikan nasional Indonesia hanya sebagai penggembira saja, sekedar tidak dikritik sekuler oleh kalangan Ulama. Bandingkan dengan di negeri-negeri Islam lainnya. Jam pelajaran Pendidikan Agama di Pakistan 4 (empat) kali lipat jumlah jam pendidikan agama di Indonesia. Selain itu, mata pelajaran Ilmu Sosial bermuatan ajaran Islam, dan mata pelajaran bahasa digunakan sebagai media memperkaya Pendidikan Agama. (Asian Centre of Educational Innovation for Development, 1977). Malah di Iran 
separoh kurikulum pendidikan dasarnya adalah agama (Bureau of Research on International Educational Sistems, 1984).

Model pendidikan keimanan selama ini bersifat konvensional. Di dunia akademik pendidikan keimanan biasanya sekdedar mengajarkan sifat-sifat Allah yang 13 atau 20, Asma ul Husna, dan kajian rukun iman dengan menyebutkan dalil-dalil Al-Quran tentang keberadaan Allah, Malaikat-malaikatNya, KitabkitabNya, Rasul-rasulNya, Hari Akhir, dan qodho-qodarNya. Di sisi lain ada juga pendekatan rasional-filosofis terhadap keberadaan Tuhan dan rukun iman. Baik pendekatan konvensional ataupun rasional sebenarnya hanya mengantarkan kepada keraguan. Mengapa ragu? Karena kedua pendekatan hanya mendatangkan kontroversi yang tidak berkesudahan. Di antara kontroversi pendekatan konvensional misalnya tentang sifat Allah yang 13 atau 20 versi hanya satu sifat Tuhan. Kedua versi ini sebenarnya rasional juga, lebih tepatnya rasional klasik. Versi 13 sifat menegaskan bahwa urut-urutan mulai sifat Wujud (Ada, sedangkan makhluk diadakan), Qidam (Terdahulu, sedangkan makhluk datang kemudian), Baqa' (Kekal-Abadi, sedangkan makhluk fana`hancur), Mukholafatu lil hawaditsi (Berbeda dengan makhluk), Qiyamubu bi nafsibi (Berdiri sendiri, sedangkan makhluk diciptakan), dan seterusnya hingga Kalam (Berfirman, sepertinya sama makhluk juga bisa berbicara, tapi Berfirman Allah berbeda dengan berbicara makhlukNya) merupakan urutan yang gradual. Maksudnya, urutan pertama (sifat Wujud) merupakan sifat yang paling pokok dan mendasar. Dari sifat Wujud inilah kemudian muncul (secara rasional, bukan secara waktu) sifat Qidam, dan seterusnya muncul sifat Kalam. Sifat 20 merupakan kelanjutan logis dari sifat 13. Di sekolah, sebagaimana di pesantren, pendekatan konvensional inilah yang diajarkan. Bahkan sifat 13 atau 20 ini dihapalkan. Anak-anak dan masyarakat muslim santri umumnya menghapalnya, walau mereka kurang mengerti akan maksud sifat 13 atau 20 ini. Adapun versi hanya Satu Sifat Tuhan menegaskan bahwa segala kesempurnaan merupakan Sifat Tuhan. Sifat 13, sifat 20, atau Asma`ul Husna dipandangnya membatasi Sifat Tuhan yang Maha Sempurna. Di antara kontroversi pendekatan rasional-filosofis misalnya ayat-ayat Al-Quran, apakah benar Firman Allah ataukah Sabda Nabi? Satu mazhab mengatakan Firman Allah, sedangkan mazhab lainnya mengatakan Sabda Nabi. Kedua mazhab ini saling menyalahkan. Untungnya kedua mazhab sepakat bahwa Al-Quran adalah mutlak benarnya, tidak ada satu kata pun yang diragukan kebenarannya. Atas dasar hal ini mengapa kaum muslimin tidak merujuk langsung Al-Quran saja, padahal Kitab Suci ini punya cara sendiri di dalam meyakinkan para pembacanya. Abdurrahman An-Nahlawi (1996) mengenalkan tujuh jenis metode AlQuran dalam menyajikan kebenaran. Ketujuh jenis metode ini oleh dosendosen PAI UPI dikembangkan menjadi model-model pembelajaran Qurani. Adapun metode yang diduga paling tepat untuk mengokohkan keimanan dan toleransi beragama mahasiswa adalah Hiwar Jadali (dialog-argumentatif Qurani). Oleh karena itulah efektivitas model pembelajaran ini perlu diteliti. 


\section{METODE PENELITIAN}

Metode yang digunakan dalam penelitian ini adalah deskriptif analisis sesuai dengan karakteristik penelitian ini yang berupaya untuk mengembangkan bahan literasi sebagai bahan pembelajaran PAI. Hal ini sesuai dengan pengertian dari metode deskriptif analitis menurut Sugiono yaitu suatu metode yang berfungsi untuk mendeskripsikan atau memberi gambaran terhadap objek yang diteliti melalui data atau sampel yang telah terkumpul sebagaimana adanya tanpa melakukan analisis dan membuat kesimpulan yang umum. Secara lengkapnya, metode deskriptif analitis yaitu suatu metode penelitian dengan mengungkapkan masalah yang ada, mengolah data, menganalisis, meneliti dan menginterprestasikan serta membuat kesimpulan dan memberi saran yang kemudian disusun pembahasannya secara sistematis (Sugiyono, 2009).

Dengan kata lain penelitian deskriptif analitis yaitu mengambil masalah atau memusatkan perhatian kepada masalah-masalah sebagaimana adanya saat penelitian dilaksanakan, hasil penelitian yang kemudian diolah dan dianalisis untuk diambil kesimpulannya untuk umum.

\section{HASIL PENELITIAN DAN PEMBAHASAN}

\section{A. Deskripsi Model Pembelajaran Hiwar Jadalī}

Pendidikan keimanan berbeda dengan pendidikan ibadah dan akhlak mulia, terlebih-lebih lagi berbeda dengan pendidikan sain dan vokasional. Pendidikan keimanan perlu menggunakan model khusus pendidikan keimanan. Al-
Quran bukan sekedar berisi ajaran aqidah, syari ah, dan akhlak saja, melainkan berisi juga tentang metodologinya, yakni metodologi menanamkan keimanan, ibadah, dan akhlak mulia. Jika dikembangkan ke dalam model-model pembelajaran, maka model yang paling tepat untuk menanamkan dan memperkokoh keimanan adalah biwar Qurani, lebih tepatnya Hiwar Jadali.

Secara terminologis, hiwar dapat diartikan sebagai dialog, yakni percakapan silih berganti antara dua pihak atau lebih melalui Tanya jawab mengenai suatu topik mengarah kepada satu tujuan. Demikianlah kedua pihak saling bertukar pendapat tentang suatu perkara tertentu. Terkadang keduanya sampai pada suatu kesimpulan, atau mungkin pula salah satu pihak tidak merasa puas dengan pembicaraan yang lain. Namun demikian ia masih dapat mengambil pelajaran dan menentukan sikap bagi dirinya (AnNahlawi, 1996: 284). Dari definisi tersebut di atas, maka dapat disimpulkan bahwa metode hiwwar Qurani adalah suatu dialog interaktif yang terdapat dalam AlQuran, terjadi antara dua pihak atau lebih dengan cara melakukan tanya jawab tentang suatu hal dan dalam satu tujuan yang sama.

Adapun Hiwar Jadalī menggambarkan suatu diskusi atau perdebatan yang bertujuan untuk memantapkan hujjah kepada para peserta diskusi. Selain dimaksudkan agar mereka mengakui pentingnya beriman kepada Allah dan mentauhidkan-Nya, juga meyakini kebenaran hari akhir dan risalah Muhammad Saw dan kebenaran sabdanya (Fahrudin, 2018a). Salah satu contoh Hiwar Jadali terdapat dalam QS Al-Anbiya 
ayat 52-71 tentang perdebatan Nabi Ibrahim dengan kaumnya yang menyembah patung-patung (Digital Quran ver 3.1, 2013). Metode pencarian secara komprehensif bias menggunakan pendekatan "Tematik Digital Quran." Cara mengoperasikannya bisa merujuk karya temuan Munawar Rahmat, "Model/Metode Pembelajaran Digital Quran Secara Tematik" (Munawar Rahmat, 2017). Adapun contoh implementasinya bisa merujuk "Understanding the Meaning of Khalifah fil ardhi in the Quran and Implications on Education" (M. Rahmat \& Fahrudin, 2018).

Hiwar Jadali mempunyai banyak impikasi pedagogis yang sama dengan dua biwar lainnya, di samping impikasiimplikasi lainnya. Adapun yang terpenting adalah:

1. Hiwar Jadalì mendidik semangat menegakkan kebenaran, memilih yang benar dan senang terhadap hujjah yang mematahkan. Semua ini termasuk perasaan-perasaan ketuhanan yang harus diperhatikan penanamannya pada anak-anak.

2. Dengan jalan pengisyaratan, Hiwar Jadali mendidik penolakan terhadap kebathilan, pikiran-pikiran yang musyrik dan mungkar, serta kerendahan dan kebathilan pikiranpikiran.

3. Hiwar Jadali mendidik akal supaya berpikir sehat dan mencapai hakikat dengan metode berpikir yang benar, seperti metode-metode berikut ini:

a. Pertama, metode hashr atau biasa disebut "ats-tsalits al-marfu" (yang ketiga yang diangkat). Jika suatu masalah mempunyai tiga macam pemecahan dan tidak ada pemecahan keempat, kemudian kita menggugurkan dua pemecahan, maka dapat ditentukan bahwa yang ketiga itulah kebenaran yang kita angkat dan kita pegang.

b. Kedua, metode qiyas (analogi) yang benar.

c. Ketiga, salah satu keistimewaannya yang paling penting ialah bahwa metode ini mendidik akal supaya berpikir objektif-realistis, dan mengemukakan hujjah-hujjah dari hal yang konkrit kepada hal yang dicari dan abstrak. Sebagai contoh lainnya adalah kisah Ibrahim bersama Namruz yang diungkapkan dalam QS 2/AlBaqarah ayat 258 (Fahrudin, 2018a).

Model umum pembelajaran mengikuti Joyce \& Weil (2009) dan Dahlan (1990). Adapun langkah-langkah model pembelajaran Hiwar Jadali mengikuti langkah-langkah model pembelajaran Kisah Qurani (Rahmat, Supriadi \& Fahrudin, 2016) dan TarghibTarbib ( Rahmat, 2018), yakni dimulai dengan menyebutkan tema/pokok bahasan, yakni kisah seorang atau beberapa orang tokoh dan kisah suatu kaum atau bangsa dalam Al-Quran (sebutkan surat ... ayat ... s.d. ...) secara utuh. Dalam rencana pembelajaran, tokoh yang akan dikisahkan, misalnya, kisah Nabi Ibrahim tentang patungpatung yang disembah oleh kaumnya dalam QS 21/Al-Anbiya ayat 52-71 atau kisah Nabi Ibrahim (Ibrahim kecil) mencari Tuhan dalam QS 6/Al-An`am ayat $\quad$ 74-79. Langkah-langkah pembelajaran sbb: 
1. Membacakan ayat-ayat Al-Qur'an yang berkaitan dengan kisah. Contohnya membacakan QS 21/Al-Anbiya ayat 52-71 atau QS 6/Al-An`am ayat 74-79.

2. Menterjemahkan ayat-ayat Al-Qur'an yang berkaitan dengan kisah. Contohnya membacakan terjemah QS 21/Al-Anbiya ayat 52-71 atau QS 6/Al-An am ayat 74-79.

3. Seorang mahasiswa ditunjuk untuk membacakan ayat demi ayat, dan mahasiswa lainnya mengikuti bacaan salah seorang mahasiswa yang ditunjuk. Jika ayatnya panjang, maka dosen meminta mahasiswa untuk memenggalnya menjadi potonganpotongan ayat yang lebih pendek.

4. Dosen menjelaskan ayat-ayat AlQur'an yang berkaitan dengan kisah. Dalam contoh sesuai urutan ayat, pertama kali dikisahkan Ibrahim terkagum-kagum melihat bintang. Dia mengira bintang itu sebagai Tuhan. Tapi kemudian muncul bulan dan bintang pun menghilang. Ibrahim mengatakan "aku tidak suka yang tenggelam". Ia pun kemudian menoleh bulan dan mengiranya sebagai Tuhan. Tapi di pagi hari cahaya bulan menyusut kemudian hilang ditelan cahaya matahari. Ia pun gembira melihat matahari. Ini Tuhanku. Ini lebih besar, kata Ibrahim. Tapi di sore hari cahaya matahari semakin berkurang, kemudian hilang ditelan kegelapan malam. Ibrahim pun akhirnya berlepas diri dari semua itu. Ia menemukan Tuhan yang sebenarnya yakni Tuhan pencipta langit dan bumi. Referensi kisah dikutip dari Ibn Katsir (2014), Tim Gema Insani (2014), Wikipedia.org
(2013) dan Quran.al-shia.org (2013). Pada tahap penjelasan ini pun dosen melakukan pendekatan dialogis. Sisipan-sisipan pertanyaan diajukan kepada mahasiswa, maksudnya selain supaya mereka memperhatikan penjelasan dosen - juga untuk mengevaluasi apakah mahasiswa dapat menangkap pesan kisah Qurani;

5. Mengukur penguasaan mahasiswa tentang isi dari penggalan surat tersebut (QS 21/Al-Anbiya ayat 52-71 atau QS 6/Al-An`am ayat 74-79) dengan cara bertanya yang diharapkan dapat dijawab oleh mereka.

6. Meminta mahasiswa untuk mengungkapkan pesan dan sikapnya terhadap kisah tersebut. Dari contoh kisah Ibrahim kecil mencari Tuhan, pesan yang diharapkan ditangkap oleh mahasiswa adalah: (1) Tidak boleh menuhankan bintang, tidak boleh menuhankan bulan, tidak boleh menuhankan matahari, sebagaimana Ibrahim kecil pun akhirnya melepaskan diri dari bintang, bulan, dan matahari; (2) Tuhan yang sebenarnya adalah Tuhan pencipta bintang, Tuhan pencipta bulan, Tuhan pencipta matahari, Tuhan pencipta langit dan bumi, dan Tuhan pencipta alam semesta; (3) Tuhan yang benar itu adalah Tuhan yang namaNya Allah; (4) Tidak boleh menuhankan apa saja selain Allah.

\section{B. Spesifikasi Model Pembelajaran Studi Agama-agama Berbasis Al- Quran di Masa Pandemic Covid 19 Melalui Pembelajaran Online}


Model pembelajaran Hiwar Jadali mempunyai ciri-ciri khas yang berbeda dengan model-model pembelajaran Pendidikan Agama Islam lainnya. Adapun spesifikasi yang paling menonjol sebagai berikut. Pertama, ditetapkannya tujuan pembelajaran Pendidikan Agama Islam (dengan model pembelajaran "Hiwar Jadali’) agar mahasiswa memahami ayatayat Hiwar Jadali untuk mengokohkan keimanannya sekaligus toleran terhadap agama dan mazhab Islam lainnya yang berbeda; dan kedua, dipilihnya ayat-ayat Hiwar Jadali, pada saat uji-coba model ini QS 2/Al-Baqarah ayat 120-139. Adapun langkah-langkah pembelajarannya sbb:

1. Mahasiswa membaca QS 2/AlBaqarah ayat 120-139 secara tartil. Usahakan masing-masing mahasiswa membacanya dengan sikap tunduk merendahkan diri disertai do`a semoga Allah SWT memberikan rahmat dan berkahNya:

2. Mahasiswa membaca terjemahan QS 2/Al-Baqarah ayat 120-139 secara perlahan.

3. Mahasiswa menelaah makna tersurat dan tersirat dari terjemahan QS 2/AlBaqarah ayat 120-139 secara perlahan dengan sikap tunduk merendahkan diri disertai do`a semoga Allah SWT memberikan pemahaman yang benar akan pesan-pesan setiap ayat yang ditelaahnya.

Adapun perkuliahan di masa pandemic Covid-19 ini dilakukan secara online melalui Zoom, WhatsApp, dan Google.Formulir. Langkah-langkah perkuliahan pada kelas uji-coba dimulai bulan Mei 2020 setelah diberlakukannya PSBB, sebagai berikut:
1. Pertemuan pertama melalui Zoom, lebih sebagai pengantar untuk pertemuan-pertemuan berikutnya agar mahasiswa di rumah masingmasing: Pertama, membaca QS 2/AlBaqarah ayat 120-139 dengan sikap tunduk merendahkan diri; Kedua, membaca terjemahan QS 2/AlBaqarah ayat 120-139 secara perlahan; dan ketiga, memahami pesan Hiwar Jadali antara:

a. Hiwar Jadali Allah dengan Nabi Muhammad dalam QS 2/AlBaqarah ayat 120 dalam menyikapi orang-orang Yahudi dan Kristen (Nasrani);

b. Hiwar Jadali Allah dengan Bani Israel dalam QS 2/Al-Baqarah ayat 121-123 tentang perlunya membaca Al-Kitab dengan benar, tentang nikmat-nikmat yang telah Allah berikan kepada Bani Israel, dan perlunya waspada akan Hari Akhir;

c. Hiwar Jadali Allah dengan Nabi Ibrahim dalam QS 2/Al-Baqarah ayat 124 tentang diangkatnya Ibrahim sebagai Imam dan permohonan Ibrahim agar anakcucu dan keturunannya juga dijadikan Imam;

d. Hiwar Jadali Allah dengan Nabi Ibrahim dan Nabi Isma il dalam QS 2/Al-Baqarah ayat 125 tentang keharusan membersihkan Ka`bah (dari kotoran-kotoran syirik).

e. Permohonan Nabi Ibrahim dan Nabi Isma il dalam QS 2/AlBaqarah ayat 126-128 agar: (1) negeri tempat tinggalnya dijadikan aman sentosa dan penduduknya diberi rizki yang baik; (2) amal- 
amalnya diterima; dan (3) dirinya dan anak-cucunya dijadikan orang-orang yang tunduk-patuh kepada Allah, diberi petunjuk tentang tata-cara ibadah haji, dan diterimanya taubat-taubatnya.

f. Permohonan Nabi Ibrahim kepada Allah dalam QS 2/AlBaqarah ayat 129 agar anak-cucu dan keturunannya dijadikan seorang Rasul (di setiap zamannya) yang mengajarkan AlKitab, Al-Hikmah, dan AnNubuwah.

g. Perintah Allah kepada Nabi Ibrahim, juga himbauan Nabi Ibrahim kepada anak-anaknya, dan seterusnya anak-cucu Nabi Ibrahim kepada generasi berikutnya dalam QS 2/AlBaqarah ayat 130-135 agar memilih agama Islam, dalam arti tunduk-patuh hanya kepada Allah semata, karena hanya agama Islam yang diajarkan oleh Nabi Ibrahim dan oleh para Nabi/Rasul pelanjut Nabi Ibrahim-lah satu-satunya agama yang lurus; sedangkan agama peninggalan Nabi, yakni agama Nabi yang dipersepsi oleh umatnya - seperti agama Yahudi dan Kristen - pasti mengandung unsur salah (tidak mungkin benar $100 \%$ ).

h. Hiwar Jadali Allah dengan orangorang beriman dalam QS 2/AlBaqarah ayat 136 agar orangorang beriman tidak membedabedakan antara satu Rasul dengan Rasul lainnya. Maksudnya, tidak membedakan Rasul yang ditemuinya dengan Rasul terdahulu.

i. Hiwar Jadali Allah dengan orangorang beriman dalam QS 2/AlBaqarah ayat 137-138 agar orangorang beriman mengimani Rasul, jangan sampai berpaling dari Rasul (biasanya karena membandingkannya dengan Rasul terdahulu)

j. Hiwar Jadalī para Nabi/Rasul dengan para penganut Nabi terdahulu dalam QS 2/AlBaqarah ayat 139 agar orangorang yang beriman kepada Rasul menegaskan "lana a imaluna wa lakum a 'malukun" (bagi kami amalan kami dan bagi kamu amalan kamu). Inilah prinsip toleransi beragama yang dibangun oleh Rasul-Rasul, karena keyakinan religious itu tidak bisa dipaksanakan (la ikraha fid-din = tidak ada paksanaan dalam agama; lakum dinukum waliyadin $=$ bagimu agamamu dan bagiku agamaku).

Pada pertemuan pertama dibahas pula tentang terbentuknya agama Yahudi dan Kristen. Dijelaskan kepada mahasiswa bahwa agama Yahudi adalah agama Nabi Musa yang di"persepsi" oleh sahabat/murid Nabi Musa, kemudian agama yang di"persepsi"nya itu diajarkan dan dilestarikan oleh para ulama berikutnya hingga terbentuk agama Yahudi hingga sekarang. Adapun sumber/referensi abadi bagi umat Yahudi adalah Kitab Taurat. Sementara agama Kristen adalah agama Nabi Isa yang di"persepsi" oleh sahabat/murid Nabi 
Isa, kemudian agama yang di"persepsi"nya itu diajarkan dan dilestarikan oleh para ulama berikutnya hingga terbentuk agama Kristen hingga sekarang. Adapun sumber/referensi abadi bagi umat Kristen adalah Kitab Taurat (Perjanjian Lama) dan Injil (Perjanjian Baru), yang lebih dikenal dengan sebutan Bibel.

Ditegaskan kepada mahasiswa, bahwa agama Nabi Musa yang benar hanyalah agama yang diajarkan dan diteladankan oleh Nabi Musa, sedangkan agama Yahudi karena hasil "persepsi" umatnya

2. Pertemuan kedua melalui WhatsApp, mengkaji Hiwar Jadali Allah dengan Nabi Muhammad dalam QS 2/AlBaqarah ayat 120-123. Tapi mahasiswa harus membaca dan memahami seluruh ayat-ayat Hiwar Jadalī ini (hingga ayat 139). Pertanyaan yang diajukan kepada mahasiswa: (a) Apakah agama yang diturunkan Allah kepada Nabi Muhammad sama dengan agama yang Allah turunkan kepada Nabi Musa dan Nabi Isa? Coba hubungkan dengan ayat 129-nya! (b) Apakah agama yang di"persepsi" oleh umat seorang Nabi benar 100\% sebagai agama yang dipahami oleh Nabinya? Apakah agama Yahudi sama 100\% dengan agama yang diajarkan dan diteladankan oleh Nabi Musa? Apakah agama Kristen sama 100\% dengan agama yang diajarkan dan diteladankan oleh Nabi Isa? (c) Mungkinkah Nabi Muhammad beragama Yahudi atau Kristen? (d) Apakah orang Yahudi dan Kristen yang membaca Al-Kitab dengan benar akan beriman kepada Nabi Muhammad? Jawaban nomor ini sebaiknya kaitkan dengan QS 2/AlBaqarah ayat 136-138.

Jawaban yang dikehendaki dari mahasiswa:

a. Agama yang diturunkan Allah kepada Nabi Muhammad adalah sama persis dengan agama yang Allah turunkan kepada Nabi Musa dan Nabi Isa, karena masing-masing Nabi/Rasul selalu disertai Al-Kitab, Al-Hikmah, dan An-Nubuwah

b. Agama yang benar hanyalah agama Allah yang diturunkan kepada Nabi Muhammad, yang dipahami, diajarkan, dan diteladankan oleh Nabi Muhammad; juga agama para Nabi/Rasul terdahulu yang dipahami, diajarkan, dan diteladankan oleh masing-masing Nabi terdahulu. Adapun agama yang tidak bersumber langsung dari Nabi, yakni agama yang di"persepsi" oleh umatnya setelah wafatnya Nabi seperti agama Yahudi dan Kristen pasti ada salahnya (tidak benar 100\%).

c. Karena sebagai sumber dan teladan agama, Nabi Muhammad tidak mungkin mengikuti orangorang Yahudi yang menginginkan Nabi Muhammad mengikuti agama Yahudi. Demikian juga Nabi Muhammad tidak mungkin mengikuti orang-orang Kristen yang menginginkan Nabi Muhammad mengikuti agama Kristen;

d. Orang-orang yang membaca Al- 
Kitab (saat itu orang Yahudi dan Kristen) dengan bacaan yang benar, mereka beriman kepada Nabi Muhammad. Nanti di ayat 136-138 dijelaskan, mereka tidak membeda-bedakan antara satu Rasul dengan Rasul lainnya. Orang Yahudi yang beriman tidak membedakan Nabi Muhammad dengan Nabi Musa. Mereka mengatakan, Muhammad adalah Musa di zaman sekarang. Demikian juga orang Kristen yang beriman tidak membedakan Nabi Muhammad dengan Nabi Isa. Mereka mengatakan, Muhammad adalah Isa di zaman sekarang.

3. Pertemuan ketiga melalui WhatsApp, mengkaji Hiwar Jadali Allah dengan Nabi Ibrahim dan anak-cucu serta keturunannya yang dipilih Allah sebagai Nabi/Rasul dalam QS 2/AlBaqarah ayat 124-136. Tapi mahasiswa harus membaca dan memahami seluruh ayat-ayat Hiwar Jadali dari ayat 120 hingga 139. Pertanyaan yang diajukan kepada mahasiswa: (a) Apa makna gelar Imam bagi Nabi Ibrahim dan bagi anak-cucu serta keturunannya yang suci-suci dalam ayat 124? Untuk menjawab pertanyaan ini hubungkan juga dengan ayat 129 dan 136: (b) Kepada siapakah Nabi Ibrahim dan anak-cucu keturunannya yang salehsaleh berwasiat agar beragama Islam yang lurus, apakah kepada anakcucunya ataukah kepada umat di luar keluarganya? (c) Nabi Ibrahim dalam ayat 129 memohon kepada Allah untuk didatangkannya seorang Rasul.
Siapa seorang Rasul yang dimaksud, apakah Nabi Muhammad ataukah seorang Nabi/Rasul di setiap zaman pasca wafatnya Nabi Ibrahim? (d) Adakah keturunan Nabi Ibrahim yang menjadi Imam pasca wafatnya Nabi Muhammad? Jawaban terhadap pertanyaan ini bisa dihubungkan dengan QS 36/Yasin ayat 12.

Sebelum menjawab pertanyaanpertanyaan ini terlebih dahulu mahasiswa perlu mengenal istilah Rasul dalam Al-Quran. Ungkapan Rasul dalam Al-Quran kebanyakan dalam bentuk tunggal/singular, bukan jama` (plural), artinya seorang Rasul. Mengapa? Karena di setiap zaman Allah hanya mengutus seorang Rasul. Di zaman Nabi Adam hanya ada seorang Rasul yakni Nabi Adam. Di zaman Nabi Nuh hanya ada seorang Rasul yakni Nabi Nuh, dst. Kalaupun di satu zaman ada dua atau beberapa Nabi, Rasulnya hanya seorang, sedangkan yang lainnya mungkin calon Rasul atau hanya Nabi saja (tanpa menyandang jabatan Rasul). Contoh di zaman Nabi Ibrahim ada tiga Nabi: Ibrahim, Isma`il, dan Ishaq, tapi Rasulnya hanya satu yakni Nabi Ibrahim. Setelah Nabi Ibrahim wafat yang menjadi Rasul adalah Nabi Isma il; dan setelah Nabi Isma il wafat yang menjadi Rasul adalah Nabi Ishaq. Di zaman Nabi Musa ada tiga Nabi: Musa, Harun, dan Khidhir, tapi Rasulnya hanya satu yakni Nabi Musa. Nabi Harun menjadi Rasul pasca wafatnya Nabi Musa. Sementara Nabi Khidhir hanyalah seorang Nabi tanpa jabatan Rasul. 
Jawaban yang dikehendaki dari mahasiswa:

a. Makna Imam dalam QS 2/AlBaqarah ayat 124 adalah Rasul. Hal ini sesuai pula dengan permohonan Nabi Ibrahim dalam QS 2/Al-Baqarah ayat 129 dan 136 yang memohon didatangkannya seorang Rasul yang membawa Al-Kitab, AlHikmah, dan An-Nubuwah.

b. Nabi Ibrahim dan anak-cucu serta keturunannya yang saleh-saleh berwasiat kepada anak-cucunya agar menganut agama Islam yang lurus, yakni agama Islam yang bersumber dari Rasulullah, bukan agama yang di"persepsi". Makna ini bukan berarti bahwa para Nabi tidak berdakwah kepada orang lain. Para Nabi semuanya berdakwah kepada manusia yang mau menerima dakwahnya. Tapi wasiat khusus atau dakwah khusus terutama bagi anakcucunya. Hal ini memberikan pelajaran, bahwa para pendakwah janganlah lebih sibuk mendakwahi orang lain. Yang paling penting adalah mendakwahi anak-cucu dan keluarganya.

c. Makna seorang Rasul yang dimohon oleh Nabi Ibrahim adalah seorang Rasul di "setiap zaman" pasca wafatnya Nabi Ibrahim. Untuk diketahui bahwa seluruh Nabi pasca wafatnya Nabi Ibrahim adalah anak-cucu dan keturunan Nabi Ibrahim. Termasuk Nabi Musa, Nabi Isa, dan Nabi Muhammad adalah keturunan Nabi Ibrahim.

d. Do`a Nabi Ibrahim itu tidak dibatasi waktu. Artinya, Nabi Ibrahim memohon agar dari anak-cucu dan keturunannya diangkat menjadi Imam tidak berhenti pada Nabi Muhammad, tapi juga Imam-Imam pasca Nabi Muhammad. Hal ini sejalan juga dengan QS 36/Yasin ayat 12 yang menegaskan bahwa segala sesuatu telah dihimpunkan pada Imam yang nyata. Makna segala sesuatu yang paling tepat adalah Al-Kitab, Al-Hikmah, dan An-Nubuwah (sebagaimana QS 2/Al-Baqarah ayat 129). Tapi para Imam pasca Nabi Muhammad tentu bukan seorang Nabi, karena Nabi Muhammad adalah Nabi terakhir. Mereka adalah seorang Imam yang disertai Al-Kitab, AlHikmah, dan An-Nubuwah. Mungkin termasuk Ulama pewaris Nabi, yakni Ulama yang ilmunya Ilmu Nabi (yakni AlKitab, Al-Hikmah, dan AnNubuwah), ketinggian akhlak mulianya sama dengan Nabi, dst.

4. Pertemuan keempat melalui WhatsApp, mengkaji Hiwar Jadali Allah dengan orang-orang beriman dan antara para Nabi/Rasul dengan para penganut Nabi terdahulu dalam QS 2/Al-Baqarah ayat 137-139. Tapi mahasiswa harus membaca dan memahami seluruh ayat-ayat Hiwar Jadali dari ayat 120 hingga 139. Pertanyaan yang diajukan kepada mahasiswa: (a) Faktor apa yang membuat umat terdahulu beriman 
kepada Nabi Muhammad dan faktor apa juga yang membuat umat terdahulu berpaling dari Nabi Muhammad? Jawaban bisa dihubungkan dengan ayat 120; dan (b) Bagaimana sikap para Nabi terhadap umat beragama dari Nabi terdahulu? Apakah para Nabi menyesatkan dan mengkafirkan mereka ataukah bersikap toleran?

Jawaban yang dikehendaki dari mahasiswa:

a. Umat terdahulu, di zaman Nabi Muhammad adalah Yahudi dan Kristen, sangat fanatic dengan agamanya. Mereka menghendaki agar Nabi Muhammad mengikuti agama mereka, yakni menjadi Yahudi atau Kristen. Tapi mereka yang membaca Al-Kitab dengan benar, beriman kepada Nabi Muhammad.

b. Sikap para Nabi terhadap fanatisme beragama umat terdahulu adalah mengajak masing-masing pihak berpegang teguh dengan keyakinan religious masing-masing dan bersikap toleran dengan menegaskan "lana a'maluna walakum a'malukum" (bagi kami amalan kami dan bagi kamu amalan kamu). Para Nabi, walau mereka sebagai sumber agama yang benar, tidak pernah menyesatkan dan mengkafirkan penganut agama dari umat terdahulu.

5. Peremuan kelima melalui zoom membahas umat Islam pasca wafatnya Nabi Muhammad, apakah
Islamnya $100 \%$ benar sebagaimana Islam yang dipahami, diajarkan, dan diteladankan oleh Nabi Muhammad ataukah hanya Islam yang di"persepsi" saja? Jawaban pertanyaan terhadap pertanyaan ini dikaitkan dengan QS 2/Al-Baqarah ayat 120-139.

Dalam pertemuan ini dosen menjelaskan tentang Islam pasca wafatnya Nabi Muhammad. Hanya beberapa tahun setelah wafatnya Nabi umat Islam terpecah ke dalam dua golongan, Islam Sunni dan Islam Syi ah. Kedua golongan Islam ini berpegang kepada Al-Quran dan Sunnah Nabi. Adapun bagi Islam Syi ah selain bersumber tersebut juga Sunnah para Imam pasca Nabi. Bagi Syi ah Imamiyah, semacam Syi ah di Iran dan Irak, bersumber kepada 12 Imam. Bagi Islam Sunni pun sering merujuk juga kepada Sunnah para Sahabat Nabi terutama Sunnah Abu Bakar, Umar, dan Utsman. Adapun generasi berikutnya merujuk AlQuran dan hadits-hadits yang dipercayainya berasal dari Nabi, Sahabat Nabi (bagi Islam Sunni), dan para Imam (bagi Islam Syi ah).

Jawaban yang dikehendaki dari mahasiswa:

Artinya, agama Islam pada kalangan umat Islam pasca wafatnya Nabi adalah Islam yang di"persepsi" oleh umat yang mengaku Islam agamanya. Islam yang di"persepsi" ini tentu tidak mungkin sama 100\% dengan Islam yang dipahami, diajarkan, dan diteladankan oleh Nabi Muhammad. 
Memang, ada perbedaan sumber/referensi umat Islam dengan umat-umat para Nabi sebelumnya. Pertama, Al-Quran sejak diturunkannya dari Allah kepada Nabi Muhammad dihapalkan oleh banyak sahabatnya dan dituliskannya. Ketika Nabi wafat banyak sahabatnya yang masih hapal dengan seluruh ayat AlQuran. Kemudian hanya 6 bulan pasca wafatnya Nabi, Kitab Al-Quran sudah dibukukan dalam sebuah Mushaf. Para ahli sejarah menuliskan tentang peristiwa yang penting ini. Artinya, Al-Quran adalah Kitab autentik dari Allah yang diturunkan kepada Nabi Muhammad. Bahkan Imam Katolik tertinggi se Dunia, Puas Johannes Paulus II mengakui akan orisinalitas Al-Quran. Berbeda dengan Kitab Taurat dan Injil baru dibukukan ratusan tahun pasca wafatnya Nabi Musa dan diangkatnya Nabi Isa. Artinya Kitab Taurat dan Injil tidak orisinal. Ayat-ayat Taurat dan Injil belum tentu 100\% sabda Nabi Musa dan Nabi Musa, mungkin ada atau banyak ayat-ayatnya yang merupakan pemahaman para sahabat/murid Nabi Musa dan Nabi Isa juga ulama Yahudi dan Kristen.

Tapi persoalannya bukan hanya pada orisinalitas Kitab Suci melainkan pada pemahaman terhadap isi Kitab Suci. Allah dalam Al-Quran berfirman bahwa Al-Quran terdiri dari ayat-ayat mubkamat (maknanya jelas, terang benderang, tidak menimbulkan multi tafsir) dan ayat-ayat mutasyabihat (maknanya samar-samar, multi tafsir, bahkan sama sekali maknanya tidak diketahui). Adapun yang memahami ayat-ayat mutasyabihat hanyalah Allah, sebagaimana difirmankanNya dalam QS 3/Ali Imran ayat 7 berikut:

Dialah yang menurunkan Al-Kitab (Al-Quran) kepada kamu. Di antara (isi)nya ada ayat-ayat yang mubkamaat, itulah pokok-pokok isi Al-Qur'an dan yang lain (ayat-ayat) mutasyaabihaat. Adapun orang-orang yang dalam hatinya condong kepada kesesatan, maka mereka mengikuti sebahagian ayat-ayat yang mutasyaabihaat daripadanya untuk menimbulkan fitnah untuk mencari-cari ta'wilnya, padahal tidak ada yang mengetahui ta'wilnya melainkan Allah. Dan orang-orang yang mendalam ilmunya berkata: "Kami beriman kepada ayat-ayat yang mutasyaabihaat, semuanya itu dari sisi Tuhan kami". Dan tidak dapat mengambil pelajaran (daripadanya) melainkan orang-orang yang berakal.

Dalam ayat tersebut ayat-ayat mutasyabihat hanya diketahui oleh Allah. Adapun sikap orang beriman adalah "Kami beriman kepada ayatayat yang mutasyaabihaat, semuanya itu dari sisi Tuhan kami". Karena AlQuran sebagai Kitab Petunjuk maka ayat-ayat yang mutasyaabibaat itu hanya dipahamkan Allah kepada Nabi Muhammad. Jadi, sikap orang beriman tidak menafsir-nafsirkan ayat-ayat yang mutasyaabihaat. Mereka hanya memahami ayat-ayat tersebut dari penjelasan lisan Rasulullah. Umat Islam pasca wafatnya Nabi Muhammad mendapat kesulitan yang besar dalam memahami ayat-ayat 
yang mutasyaabihaat, dan kebanyakan bahkan mungkin semua ayat-ayat yang mutasyaabihaat itu tidak terekam oleh kaum muslimin. Akibatnya banyak ayat-ayat Al-Quran yang ditafsirkan secara berbeda-beda oleh satu Ulama dengan Ulama lainnya. Bahkan ayat-ayat berupa huruf-huruf Hijaiyah seperti Alif-Lam-Mim, AlifLam-Ra, Ya-Sin, Kaf-Ha-Ya-Shin'Ain-Shad dll sama sekali tidak pernah ada penjelasannya. Allah sendiri dalam Al-Quran menegaskan bahwa Al-Quran hanya bisa dipahami oleh orang-orang yang disucikanNya: "Innahu laqur'anul karim. Fi kitabin maknun. La yamassubu illal muthabharum" (Al-Quran adalah bacaan yang mulia. Tersimpan dalam Kitab yang terpelihara. Tidak ada yang bisa memahami kedalaman maknanya. Kecuali orang-orang yang disucikanNya). Para ahli penterjemah Al-Quran hanya memberikan catatan "Wallahu a lam bish-shawab" (Hanya Allah yang Mengetahui maknanya). Jadi ayat-ayat yang mutasyaabihaat tidak pernah menjadi petunjuk bagi umat Islam. Di masa pasca wafatnya Nabi Muhammad, mungkin hanya Ulama pewaris Nabi yang mengetahui kedalaman makna ayat-ayat mutasyabihat. Sikap kaum Muslimin seharusnya memohon kepada Allah agar dipahamkan dengan Al-Quran, baik terhadap ayat-ayat mubkamat maupun mutasyabihat, bukan saling menyalahkan terlebih-lebih saling menyesatkan dan mengkafirkan mazhab/golongan Islam lainnya.

Atas dasar ini, bahwa Islam pasca wafatnya Nabi Muhammad hanyalah Islam yang di"persepsi", maka tidak beralasan sedikit pun kaum Muslim Sunni menyalahkan, terlebih-lebih menyesatkan dan mengkafirkan Muslim Syìh. Demikian juga tidak beralasan sedikit pun kaum Muslim Syi ah menyalahkan, terlebih-lebih menyesatkan dan mengkafirkan Muslim Sunni. Bahkan di kalangan Muslim Sunni dan Muslim Syi ah pun muncul mazhab-mazhab dan golongan-golongan yang berbedabeda. Tidak beralasan sedikit pun kaum Muslim dari satu mazhab/golongan menyalahkan, terlebih-lebih menyesatkan dan mengkafirkan Muslim lainnya dari mazhab/golongan Muslim lainnya lagi. Masing-masing mazhab/ golongan Islam sudah seharusnya bersikap rendah hati disertai selalu memohon ampunan Tuhan karena dirinya sadar dengan sesadar-sadarnya terbukti dirinya dan mazhabnya/golongannya tidak memahami ajaran Islam secara utuhsempurna karena banyaknya ayat-ayat Al-Quran yang mutasyabihat. Dari sikap ini kemudian muncul saling menghormati keyakinan religious masing-masing mazhab/golongan Islam dan membangun persaudaraan sejati sebagai sesama Muslim. Di kalangan Muslim berbagai mazhab/golongan seharusnya terbangun ukhuwah Islamiyah sejati. Sikap intoleran terlebih-lebih radikal beragama sama sekali tidak memiliki dasar sedikit pun.

6. Sehari setelah pertemuan kelima mahasiswa mengisi instrument 
penelitian via google.formulir, sejauh manakah mereka memahami pesanpesan dari ayat-ayat Hiwar Jadali dalam QS 2/Al-Baqarah ayat 120139.

\section{KESIMPULAN}

Hiwar Jadali adalah dialog-argumentatif Qurani. Dalam hal ini pihak-pihak yang berdialog umumnya Allah SWT dengan para NabiNya, dengan orang-orang beriman, ahli kitab, manusia pada umumnya, dan orang-orang kafir; juga antara Nabi dengan orang-orang beriman, ahli kitab, dan orang-orang kafir; juga antara orang-orang beriman dengan ahli kitab dan orang-orang kafir.

Spesifikasi model pembelajaran Hiwar Jadali di masa pandemic Covid-19 ini: Pertama, perkuliahan dilakukan secara online melalui Zoom, WhatsApp, dan Google.Formulir; kedua, tujuan pembelajaran agar mahasiswa memahami ayat-ayat Hiwar Jadali untuk mengokohkan keimanannya sekaligus toleran terhadap agama dan mazhab Islam lainnya yang berbeda. Ayat Hiwar Jadali yang dipilih dalam uji-coba model ini QS 2/Al-Baqarah ayat 120-139.

Langkah-langkah pembelajaran. Pertemuan pertama, melalui zoom, menjelaskan tugas-tugas yang harus dilakukan mahasiswa di rumah masingmasing menyangkut Hiwar Jadalī dalam QS 2/Al-Baqarah ayat 120-139 (mulai membacanya dengan sikap tunduk merendahkan diri, menterjemahkannya secara perlahan, dan memahami penggalan-penggalan ayat-ayatnya) dan penjelasan singkat tentang agama Yahudi dan Kristen. Pertemuan kedua, melalui WhatsApp, membahas dan merenungkan makna Hiwar Jadali dalam QS 2/AlBaqarah ayat 120-123. Pertemuan ketiga, melalui WhatsApp, membahas dan merenungkan makna Hiwar Jadalì dalam QS 2/Al-Baqarah ayat 124-136. Pertemuan keempat, melalui WhatsApp, membahas dan merenungkan makna Hiwar Jadalī dalam QS 2/Al-Baqarah ayat 137-139. Pada setiap pertemuan ditekankan tentang makna beriman yang benar dan perlunya toleransi beragama. Pada pertemuan kelima membahas umat Islam pasca wafatnya Nabi Muhammad SAW yang terdiri dari beragam mazhab dan golongan. Masing-masing mazhab/golongan perlu: (1) bersikap merendah dan memohon ampunan Tuhan karena terbukti tidak bisa memahami ajaran Islam yang benar-benar dipahami, diajarkan, dan diteladankan oleh Rasulullah; (2) saling menghormati keyakinan religious mazhab/golongan Islam lainnya; dan (3) membangun ukhuwah Islamiyah yang sejati. Sehari setelah pertemuan kelima, melalui google.formulir, mahasiswa mengisi/ menjawab sejumlah pertanyaan untuk mengukur keperhasilan model.

\section{Acknowledgement}

Terima kasih disampaikan kepada Rektor Universitas Pendidikan Indonesia yang telah membiayai penelitian kami, Dana Rencana Kerja dan Anggaran Tahunan Penugasan Lembaga Penelitian dan Pengabdian Kepada Masyarakat Universitas Pendidikan Indonesia Tahun Anggaran 2020 Dengan Surat Keputusan Rektor Nomor: 1079/UN40/PM/2020.

\section{REFERENSI}

Anasari, T. (2009). Membuat Media Pembelajaran Pembuatan Blog Berbasis 
Multimedia Pada SMK Negeri 1

Gondang Sragen. 1(3), 57-66.

Chaidar, H. (2014). Pemanfaatan

Teknologi Informasi dan

Komunikasi dalam Pembelajaran di

SMA Muhammadiyah Tarakan.

Jurnal Kebijakan Dan Pengembangan

Pendidikan, 2(2), 184-192.

Dwi Irmawati, Sriyono, A. B. S. (2012).

Studi Eksperimen Pemanfaatan

Blended Learning Model Berbasis

Web Sebagai Sumber Belajar

Geografi. Edu Geography, 1(2).

Komputer, W. (2015). Membuat Toko Online dengan Wordpress dan WP ECommerce. Elex Media Komputindo. https://books.google.co.id/books?i $\mathrm{d}=6 \mathrm{k} 1 \mathrm{JDwAAQBAJ} \&$ printsec $=$ fro ntcover\&dq $=$ membuat + toko + onlin $\mathrm{e}+$ dengan + wordpress + dan $+w p+e-$ commerce\&hl $=$ en\&sa $=$ X\&ved $=0$ ah UKEwjpncfi67LnAhWXbX0KHS41 BaAQ6AEIKTAA $\#_{\mathrm{v}}=$ onepage\&q $=$ membuat toko online dengan wordpress dan wp ecommerce $\& \mathrm{f}=\mathrm{fa}$

Suhartono. (2017). Menggagas Penerapan Pendekatan Blended Learning Di Sekolah Dasar Subartono BLENDED LEARNING APPROACH INITIATING APPLICATION Instructional media such as books, globes, and other students are learning in Menggagas Penerapan Pendekatan Blended Learning Di.

Surahman, C. (2019). Tafsir Tarbawi in Indonesia: Efforts to Formulate Qur'anBased Islamic Education Concept. Jurnal Pendidikan Islam, 5(2), 211-226. 